\title{
Urease Mediated Synthesis of Crystalline Porous Tin Oxide at Room-temperature and Applications in Lithium-ion Batteries and Gas Sensors
}

\author{
Ge Chen \\ Beijing Key Laboratory for Green Catalysis and \\ Separation, College of Environmental \& Energy \\ Engineering \\ Beijing University of Technology \\ Beijing, P.R. China. \\ e-mail: chenge@bjut.edu.cn
}

\author{
Qiang Zhang \\ Beijing Key Laboratory for Green Catalysis and \\ Separation, College of Environmental \& Energy \\ Engineering \\ Beijing University of Technology \\ Beijing, P.R. China. \\ e-mail: 2436633645@qq.com
}

\begin{abstract}
In the absence of urea, urease is demonstrated to catalyze the hydrolysis and polycondensation of the $\mathrm{SnCl}_{2}$ aqueous system to form crystalline mesoporous $\mathrm{SnO}_{2}$ at room temperature. The resulting $\mathrm{SnO}_{2}$ has a high specific surface area of $231 \sim 248 \mathrm{~m}^{2} \mathrm{~g}^{-1}$ with uniform pore size at $3.3 \mathrm{~nm}$, and the porous structure show high thermal stability. Interestingly, the urease is not co-precipitated with the tin oxide but is left in solution, which indicates the high purity of tin oxide and the possibility for urease recovery. The characterization of inter-mediates and final products reveal the key feature of strategy presented in this study is the stabilization of an amorphous tin oxide phase by urease and its subsequent transformation to crystalline tin oxide; the phase transformation and removal of water might be the major reasons for pores forming process. And the obtained tin oxides exhibit not only enhanced electrochemical performance in lithium ion battery, but also better sensitivity toward hydrogen.
\end{abstract}

Keywords: urease; biomimetic synthesis; porous tin oxide; gas sensor; lithium ion battery

\section{INTRODUCTION}

$\mathrm{SnO}_{2}$ is one of the most intensively studied oxide semiconductors due to its myriad technologically important applications. To date, a wide variety of $\mathrm{SnO}_{2}$ nanostructures, such as nanoparticles ${ }^{[1]}$, nanowires ${ }^{[2]}$, nanotubes ${ }^{[3]}$, hollow spheres ${ }^{4]}$, or porous structures ${ }^{[5]}$ have been prepared for the purpose of improving device efficiency. In particular, porous $\mathrm{SnO}_{2}$ has immense potentials for application in electrode and sensor due to its large surface area and short solid-state diffusion length ${ }^{[5 \mathrm{~d} \text {, }}$ $5 \mathrm{e}, 5 \mathrm{~m}, 5 \mathrm{n}, 5 \mathrm{o}]$. The generally reported synthetic approaches of porous $\mathrm{SnO}_{2}$ involve the crystallizations and pores forming process ${ }^{[5]}$. The crystallizations are often realized by heat treatments (calcinations, hydrothermal process, microwave treatment, etc) and the hard templates (KIT-6 ${ }^{[5 \mathrm{n}]}$ ) or soft templates ${ }^{[5 \mathrm{~h}-5 \mathrm{~m}]}$ (organic materials) are used for forming porous structure. Recently, template-free syntheses (nanoparticles assembly [5a, 5d], sol-gel ${ }^{[5 \mathrm{e}-5 \mathrm{~g}]}$, hydrothermal method ${ }^{[5 \mathrm{~b}, 5 \mathrm{c}]}$ ) of porous tin oxides have been reported. However, the room-temperature synthesis of crystalline porous tin oxide is a challenging task because the crystallization and pores forming process are hardly carried out in such a mild environment. And the development of benign synthetic pathways to porous tin oxides is of great importance in the context of greenchemistry principles, and for potential scale up in energy efficient ways.

On the other hand, methods that mimic biomineralization have received a great deal of attention because of nature's ability to produce interesting nanostructures under inherently benign and energyconserving conditions. Morse and co-workers firstly demonstrated that biomolecules implicated in biosilicification could be utilized to induce the formation of nonbiogenic inorganic oxides ${ }^{[6]}$. Following this initial study, the use of biomolecules to direct the in vitro syntheses of non-biological oxide is a rapidly developing field in which the synthesis of nanoscale materials is often facilitated by the presence of biomolecules ${ }^{[7]}$. More interestingly, the size, shape, and polymorphs of obtained oxides can be tailored by bio-molecules. For example, Kröger used different recombinant silaffin to induce the formation of rutile or monoclinic $\beta-\mathrm{TiO}_{2}$ under ambient conditions and neutral $\mathrm{pH}^{[8]}$; de la Rica applied the urease as a nanoreactor for synthesis of $\mathrm{ZnO}$ nanoshells through the control of hydrolysis of urea ${ }^{[9]}$; and Douglas reported the synthesis of size- and shape-constrained partially crystallized $\beta-\mathrm{TiO}_{2}$ by using protein cage architectures of a viral capsid ${ }^{[10]}$.

Herein, we demonstrated a completely novel synthetic pathway to crystalline porous tin oxides by using jack bean urease as bio-inspired molecule in a tin dichloride solution at room temperature. For the first time, the nanoporous structures for non-biological oxides are reported by the direction of bio-molecule at room temperature. The 
jack bean urease is composed of six $90 \mathrm{KDa}$ subunits $(840$ residues), and has an isoelectric point of $4.9^{[11]}$. Besides its biocatalytic property for decomposing urea, the jack bean urease also have high affinity for metal ions due to its abundant surface chemical moieties ${ }^{[12]}$. And it has been demonstrated that chemical moieties of nucleophilic hydrogen-bonded hydroxyl group and hydrogen-bonded carboxyl groups catalyzed hydrolysis reactions [13]. Inspired by this idea, we attempt to use urease just as biotemplate (no urea is needed in the whole synthetic procedure) for growth of tin oxides. Aqueous solutions of tin dichloride when reacted with jack bean urease resulted in the synthesis of crystalline porous tin oxide with high surface areas and narrow pore size distribution. The intermediate and final products were analyzed by X-ray diffraction (XRD), Nitrogen sorption, Transmission electron microscopy (TEM), X-ray photoelectron spectroscopy (XPS). These techniques reveal that the key feature of strategy presented in this study is the stabilization of an amorphous tin oxide shell by urease and its subsequent transformation to crystalline tin oxide; and phase transformation and removal of water might be the reason for pores forming process. The obtained tin oxide has a specific surface areas as high as 231 248 $\mathrm{m}^{2}$ $/ g$ with a narrow pore size distribution at $3.3 \sim 3.5 \mathrm{~nm}$ (pore volume of $0.19 \sim 0.23 \mathrm{~cm}^{3} / \mathrm{g}$ ), and the porous structure demonstrated high thermal stability even at $500^{\circ} \mathrm{C}$. This innovative method laid the groundwork for the facile production of porous tin oxides in an economical and energy-efficient way. Considering its immense potentials in gas sensor and lithium ion battery, the electrode and sensor performance of tin oxides were tested and showed enhanced cyclability in lithium ion battery and highly sensitive behavior toward $\mathrm{H}_{2}$.

\section{EXPERIMENTAL}

\section{A. Material and Synthesis}

Jack bean urease was purchased from Sigma and used without further purification. $\mathrm{SnCl}_{2} \cdot \mathrm{H}_{2} \mathrm{O}$ was purchased from Beijing chemical agent $\mathrm{Co}$. In a typical synthesis, $0.2 \mathrm{~g} \mathrm{SnCl}_{2} \bullet \mathrm{H}_{2} \mathrm{O}$ was added into $25 \mathrm{~mL} \mathrm{H}_{2} \mathrm{O}$; a translucent solution of $\mathrm{SnCl}_{2}$ was obtained. Then, $25 \mathrm{~mL}$ solution of urease $(1 \mathrm{mg} / \mathrm{mL}$, prepared in distilled water) was mixed with the $25 \mathrm{~mL}$ solution of translucent $\mathrm{SnCl}_{2}$. And the mixture became white turbid immediately. The solution was stirred subtlety at room temperature for 4 days; a pale yellow suspension was obtained. At the reaction time of $1 / 2,1,2,3,4$ days, the resultant particles were centrifuged at $8000 \mathrm{rpm}$ and washed with distilled water several times. After drying at $50^{\circ} \mathrm{C}$ for 8 hours, the obtained sample particles were characterized by various techniques. For comparison, the translucent solution of $\mathrm{SnCl}_{2}$ without adding urease was stirred at room temperature for 10 days. For the purpose of device performance comparison, the porous $\mathrm{SnO}_{2}$ was prepared by hydrothermal method: $0.16 \mathrm{~g}$ of $\mathrm{Na}_{2} \mathrm{SnO}_{3}$ was dissolved in $30 \mathrm{~mL}$ solution (ethanol/water $=1: 2$ ), and then $1 \mathrm{~g}$ urea was added to the above solution with vigorous stirring. After stirring for $1 \mathrm{~h}$, the solution was transferred into a autoclave and heated to $160{ }^{\circ} \mathrm{C}$, and held for $12 \mathrm{~h}$. After the hydrothermal treatment, the precipitates were collected from solution by filtering, washing several times with water and ethanol, dried in oven at $100^{\circ} \mathrm{C}$ overnight. The obtained tin oxides showed a specific surface area of $176.3 \mathrm{~m}^{2} / \mathrm{g}$ and a narrow pore size at $5.7 \mathrm{~nm}$.

\section{B. Structural Characterization}

X-ray diffraction patterns of sample powder were recorded on a Bruker D8 ADVANCE X-ray diffractometer using filtered $\mathrm{CuK} \alpha$ radiation. Transmission electron microscopy images and High resolution transmission electron microscopy images were taken with a JEOL 2010 microscope on powder samples deposited onto a copper micro-grid coated with carbon. Energy-dispersive X-ray spectrum was measured by JEOL 2010 microscope equipped with an Oxford LinkISIS energy dispersive spectroscopy analyzer. Specific surface areas were measured at $77 \mathrm{~K}$ by BrunauerEmmett-Teller nitrogen adsorption-desorption (Shimadzu, Micromeritics ASAP 2010 Instrument), and pore size distributions were calculated from the desorption branch of the $\mathrm{N}_{2}$ adsorption isotherm using the Barrett-JoynerHalenda formula. A Physical Electronics PHI Quantera SXM with monochromatized $\mathrm{AlK} \alpha$ radiation and an energy resolution of $0.5 \mathrm{eV}$ was used X-ray photoelectron spectrum analysis. Infrared (IR) spectrums were measured by Digilab FTS 7000, while Thermogravimetric (TG) analysis was measured on PerkinElmer Diamond TG/DTA.

\section{Electrochemical measurement}

For preparing working electrodes, a N-methyl pyrrolidinone (NMP) slurry consisting of $80 \mathrm{wt} \%$ of the $\mathrm{SnO}_{2}$ powder, $10 \mathrm{wt} \%$ of carbon black and $10 \mathrm{wt} \%$ polyvinylidene fluoride (Aldrich) was pasted on to pure $\mathrm{Cu}$ foil. The electrodes were vacuum dried overnight at $80^{\circ} \mathrm{C}$. Glass fiber $(\mathrm{GF} / \mathrm{D})$ from Whatman was used as a separator. Pure lithium foil (Aldrich) was used as the counter electrode, and the electrolyte used was 1 M LiPF6 in a 50:50 w/w mixture of ethylene carbonate and diethyl carbonate. Cell assembly was carried out in a recirculating argon glove box where both the moisture and oxygen contents were below $1 \mathrm{ppm}$ each. Galvostatic electrochemical experiments were carried out with a Neware Battery Tester (Shenzhen, China).

\section{Measurement of Gas-Sensing Properties}

Sensor test was conducted on a self-building sensor platform. Sensitive materials were dispersed in deionized water and dropped to UST micro heat plate devices to form a thick film with a thickness of about $5 \mu \mathrm{m}$. Synthetic air and specific standard gas $\left(\mathrm{H}_{2}\right)$ with various concentrations (diluted in synthetic air) were delivered to the test chamber (with an inner volume of about $30 \mathrm{~mL}$ ) by Mass Flow Controllers (MFCs) at the same time at a constant total rate of $200 \mathrm{sccm}$. The sensor devices were heated by an Agilent E3640A programmable DC power supply, and the resistances of the sensitive layers were acquired by a Keithley 2400 source meter. All experiments were carried out at $300{ }^{\circ} \mathrm{C}$ after a warm-up process at the same temperature for about an hour. 


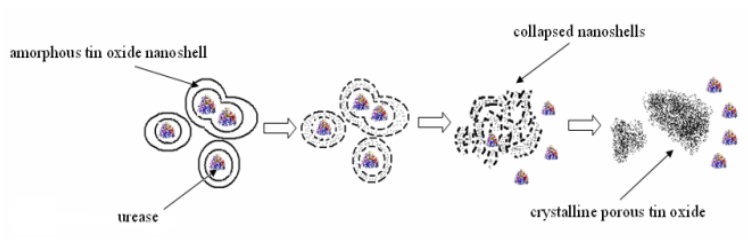

Scheme 1. Proposed mechanism for formation of crystalline porous tin oxides

\section{RESUlTS AND DisCUSSIONS}

Fig.1a shows the prepared sample particles with their crystallographic structure by using X-ray diffraction (XRD). All the broad diffraction peaks of the XRD pattern can be assigned to tetragonal rutile $\mathrm{SnO}_{2}$. The wellknown Scherer crystallite size calculated using the XRD pattern is $2.4 \mathrm{~nm}$. The low magnification Transmission electron microscopy (TEM) image shows the relative large size and irregular shape of particles, high magnification TEM image of the particles (Fig.1b) indicates the presence of a worm-hole structure; the pore size was evaluated to have a diameter of $3.0 \mathrm{~nm}$. A lattice image can be clearly seen in the High Resolution TEM image (Fig.1c), the distance between the adjacent lattice fringes corresponds to the inter-planar distance of the tetragonal $\mathrm{SnO}_{2}$ (110), which is $0.335 \mathrm{~nm}$. Figure 1d shows a typical adsorption-desorption isotherm plot for the nitrogen sorption $(77 \mathrm{~K})$ of the $\mathrm{SnO}_{2}$ sample. An obvious hysteresis loop observed in the plot is associated with the filling and emptying of mesopores by capillary condensation. The $\mathrm{SnO}_{2}$ sample exhibits a BrunauerEmmett-Teller (BET) surface area of $231.7 \sim 248.3 \mathrm{~m}^{2} \mathrm{~g}^{-1}$. Pore size distributions are then determined by the BarrettJoyner-Halenda (BJH) method applied to plot; a typical pore size distribution is shown in Fig.1d inset, which a fairly narrow size distribution, $3.2 \sim 3.6 \mathrm{~nm}$, is achieved. The high surface areas might be attributed from both small size of pore walls and pores. For the precipitate aging from pure $\mathrm{SnCl}_{2}$ solution, only amorphous peaks were observed in XRD pattern, and TEM image showed amorphous nano spheres. Besides high surface areas, high thermal stability of porous tin oxides is also desirable for many practical applications such as sensor devices; the prepared $\mathrm{SnO}_{2}$ sample were annealed at $500{ }^{\circ} \mathrm{C}$ for 2 hours in the air to examine the thermal stability. showed the XRD patterns of annealed $\mathrm{SnO}_{2}$ particles, the peak width was found to remain broad after annealing at $500{ }^{\circ} \mathrm{C}$, providing the Scherer crystallite size of $3.2 \mathrm{~nm}$ which is a litter bigger than that of as prepared tin oxides. The BET surface areas remained high after annealing; they were typically $191 \sim 197 \mathrm{~m}^{2} / \mathrm{g}$, which surpassed most reported surface area of porous tin oxide at $500{ }^{\circ} \mathrm{C}$, and BJH data exhibited similar narrow size distributions with average pore size diameters of $3.0 \sim 3.3 \mathrm{~nm}$. The slight decrease of BET surface areas and pore size diameters might be attributed to the slight grain growth of tin oxides in the annealing treatment.
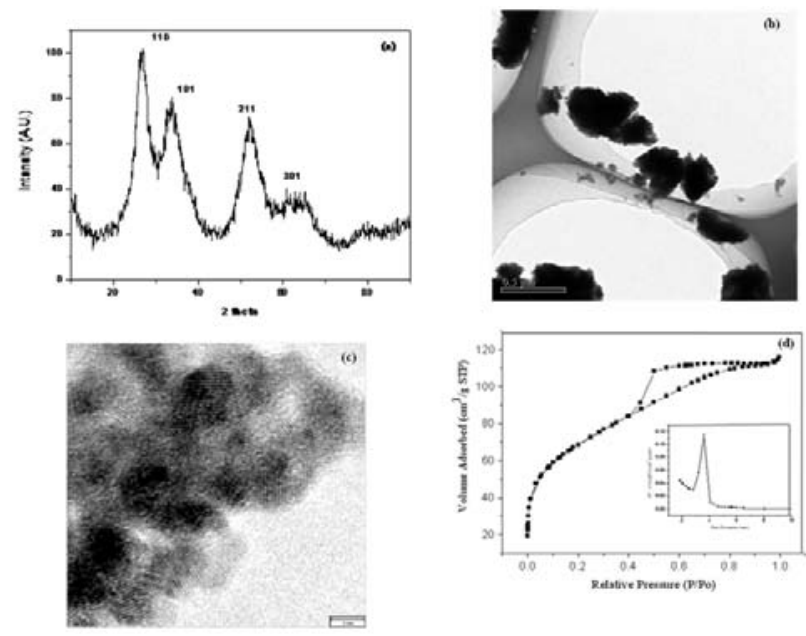

Figure 1. (a) XRD pattern of as prepared tin oxide (b) high magnification TEM images of as prepared tin oxide, bar 10nm (c) HRTEM image of as prepared tin oxide, bar $3 \mathrm{~nm}$ (d) $\mathrm{N}_{2}$ adsorption-desorption isotherm at $77 \mathrm{~K}$ of as prepared tin oxide; insert: corresponding pore size distributions calculated by BJH method.

To investigate the crystallization and pores forming mechanism of porous $\mathrm{SnO}_{2}$, the samples at different reaction time (at 1/2, 1, 2, 3, 4day, namely a, b, c, d, e, respectively) were characterized using XRD, TEM, BET, XPS techniques. Fig. 2 demonstrates the TEM images of samples, we observed many irregular shell nanostructures of sample a; this structure consists of a core of jack bean urease which is electro-transparent surrounded by a shell of tin oxide. The irregularity might be resulted from the aggregation of ureases, and the tin oxide nanoshells were growing around ureases core. The thickness of tin oxide shell is about $10 \mathrm{~nm}$, which is similar with crystalline $\mathrm{ZnO}$ nanoshells ${ }^{[9]}$. However, no diffraction rings were observed on the selected-area electron diffraction (SAED) pattern of the resulting nanoshells, suggesting the nanoshells is amorphous. With the reaction time increasing, we observed these shells became roughen (Fig. 2b), collapsed (Fig.2c) and aggregated to the large particles with worm-hole pores (Fig. 2d, 2e). The XRD pattern of samples (Fig.2) revealed the phase transformation from amorphous species to nanocrystalline of tin oxides with the reaction time increasing.

Table 1. BET surface areas and BJH pores size distributions measured for samples at different reaction time (a) 1/2 day; (b) 1 day; (c) 2 days; (d) 3 days; (e) 4 days;

\begin{tabular}{lll}
\hline sample & $\begin{array}{l}\text { BET surface } \\
\text { areas }\left(\mathrm{m}^{2} / \mathrm{g}\right)\end{array}$ & $\begin{array}{l}\text { BJH pore size } \\
\text { distribution }(\mathrm{nm})\end{array}$ \\
$\mathrm{a}$ & 87 & $20 \sim 80$ \\
$\mathrm{~b}$ & 113 & $25 \sim 60$ \\
$\mathrm{c}$ & 135 & $3.4,7 \sim 14$ \\
$\mathrm{~d}$ & 175 & $2.8 \sim 7.2$ \\
$\mathrm{e}$ & 236 & 3.3 \\
\hline
\end{tabular}




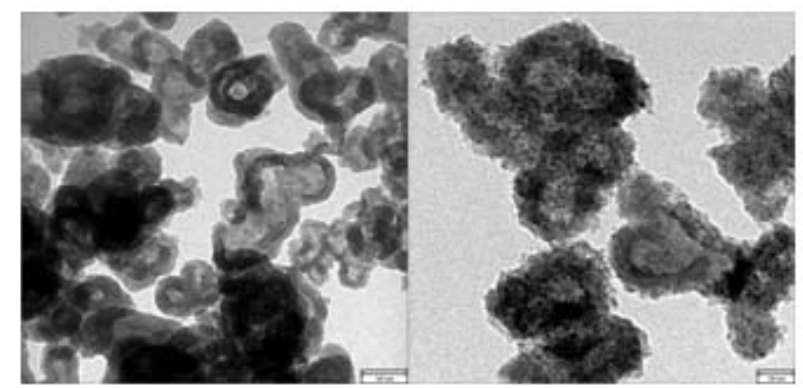

(a)

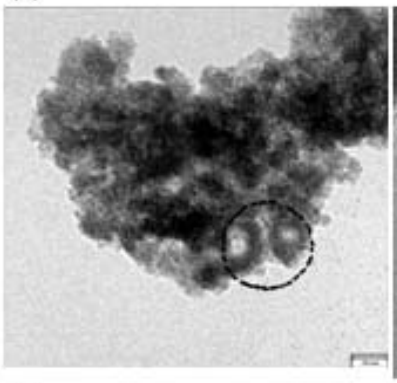

(c)

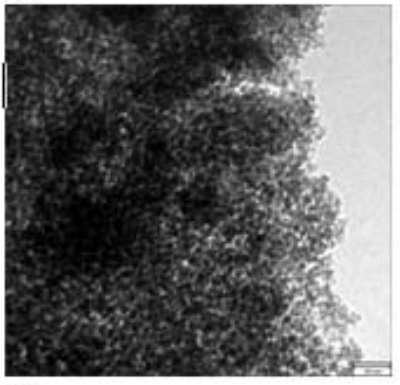

(e) (b)

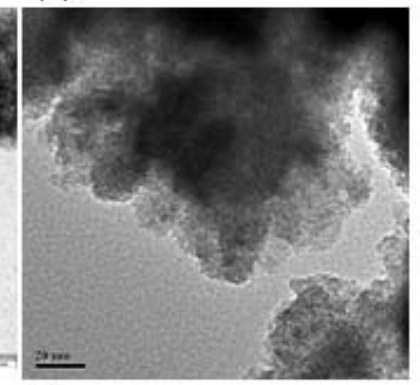

(d)

(f)

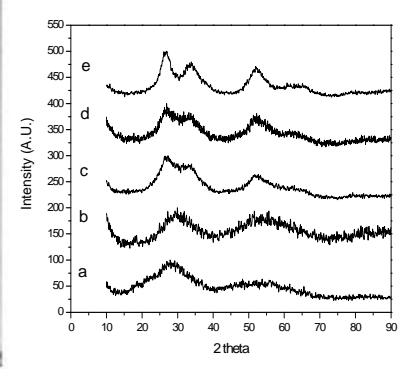

Figure 2. TEM images of samples at different reaction time (a) 1/2 day, bar 50nm; (b) 1 day, bar 20nm; (c) 2 days, bar 20nm; (d) 3 days, bar 20nm; (e) 4 days, bar $20 \mathrm{~nm}$. (f) XRD patterns of samples at different reaction time

Table 1. showed the BET surface areas and pore size distribution of samples, the surface areas increased from $87 \mathrm{~m}^{2} / \mathrm{g}$ (sample a) to $236 \mathrm{~m}^{2} / \mathrm{g}$ (sample e) gradually and the pore size decreased from sample a to sample e; the plots of nitrogen adsorption-desorption isotherms and BJH pore size distribution were given in Fig.4; the large pores $(30 \sim 60 \mathrm{~nm})$ of sample a, b might be attributed from the inner-space of nanoshell structures or the inter-spaces between nanoshells or both. As the nanoshells structure collapsed, the large pores were replaced by small pores gradually. This result agreed well with the observed TEM images. Interestingly, besides a major pore size distribution at $3.4 \mathrm{~nm}$, there is another pore size distribution at $7 \sim 14 \mathrm{~nm}$ for sample c. We believe the $3.4 \mathrm{~nm}$ pores might be arisen from phase transformation between amorphous species and primary crystallites (phase transformation from amorphous state (less dense phase) to crystalline state (more dense phase), and the pores were left behind.), and the 7 14nm pores might be formed by collapsed nanoshells aggregations. From sample $\mathrm{c}$ to sample $\mathrm{e}$, the $7 \sim 14 \mathrm{~nm}$ pores changed to

smaller pores and became uniform size at $3.3 \mathrm{~nm}$ finally. It is noteworthy that the pores forming process is accompanied with the crystallization of samples. The wide-survey XPS spectra of sample 4 reveal the presence of carbon, oxygen and tin species. The Sn 3d peaks appear around 486.8 and $495.1 \mathrm{eV}$ and are characteristic of $\mathrm{Sn}^{4+}$ in $\mathrm{SnO}_{2}$.

Fig.4 showed the XPS C 1s core level spectrum of sample1/2, 2, and 4. Besides the major band at $284.8 \mathrm{eV}$ assigned to adsorbed carbon, there is a minor band at $288.7 \mathrm{eV}$ for Sample $1 / 2$, which can be assigned to $\mathrm{C}=\mathrm{O}$ species. The existence of the $\mathrm{C}=\mathrm{O}$ species might come from amide group of polypeptides, this result suggested Sample 1/2 was a composite of tin oxides and urease. As the reaction time increased to 2, 3, 4 day, we observed the band at $288.7 \mathrm{eV}$ disappeared, which suggested the isolation of urease from composite with the gradual formation of crystalline porous $\mathrm{SnO}_{2}$. A reasonable explanation is that the pore sizes of tin oxides are more and more small than the dimension of urease $(7.5 \mathrm{~nm} \times$ $8.0 \mathrm{~nm} \times 8.0 \mathrm{~nm})$ and not accessible to bulky urease molecules. This result is of particular interesting because bio-inspired inorganic materials often remain in intimate contact with the organic catalytic template, rendering them largely unsuitable for device applications that require high purity materials; also the urease can be recovered from solution for repeat use. The sample e was further examined by Fourier Transform Infrared (FTIR) spectroscopy. It was well known that IR absorption bands centered at 1650 and $1544 \mathrm{~cm}^{-1}$ were ascribed to the typical amide I and amide II adsorption bands of polypeptide chains, respectively. Fig.3d shows FTIR spectra of the Sample 4, the peak at 3350-3450 and 1620$1630 \mathrm{~cm}$ can be assigned to the stretching vibrations of $\mathrm{OH}$ groups and bending vibrations of adsorbed molecular water, respectively. However, no bands were observed at 1650 or $1544 \mathrm{~cm}^{-1}$, this result also confirmed that the obtained $\mathrm{SnO}_{2}$ is free of urease. The thermal analysis result of the Sample e is shown in Fig. 4c, the weight loss $(1.8 \%)$ before $100^{\circ} \mathrm{C}$ corresponds to the desorption of adsorbed water, and the following weight loss can be assigned to the dehydration of hydroxyl group and elimination of organic residues, note only $6 \%$ weight lost at temperature of $800^{\circ} \mathrm{C}$, which indicated the obtained $\mathrm{SnO}_{2}$ is highly thermal stable.

On the basis of all the above observations, a simple plausible mechanism was proposed addressing the bioinspired synthesis of crystalline porous $\mathrm{SnO}_{2}$ (See Scheme 1). It was reported proteins frequently participate in crystallization processes by directing the nucleation and growth of the inorganic structure ${ }^{[14]}$. Because of its relative large areas and abundant chemical moieties, the structured organic surfaces of urease are considered to play a key role in matrix-mediated deposition by providing nucleate site and lowering the activation energy of nucleation of tin oxide. In our experiment, hydrolyzed tin species were firstly deposited on the surface of urease through a combination of covalent and electrostatic interaction and form an amorphous solid nanoshells; 

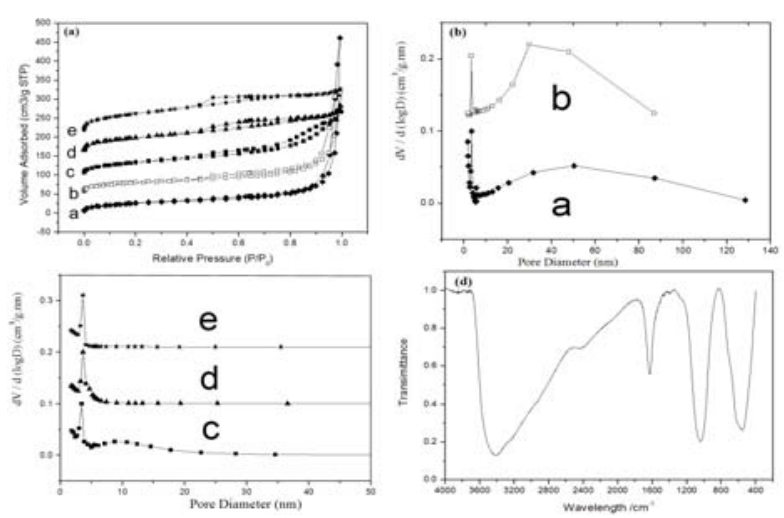

Figure 3. Nitrogen adsorption-desorption isotherms (left) and BJH pore size distribution plots (right) measured for samples at different reaction time (a), (b) ,(c), $1 / 2$ day; 1 day; 2 days; 3 days; 4 days ;(d) IR spectrum of sample e

Then, the amorphous solid nanoshells are subject to a relatively slow phase transformation process which usually occurs by dissolution-recrystallization processes closely associated with the surface and/or the interior of preformed particles; then the shells collapsed and aggregated to large particles.

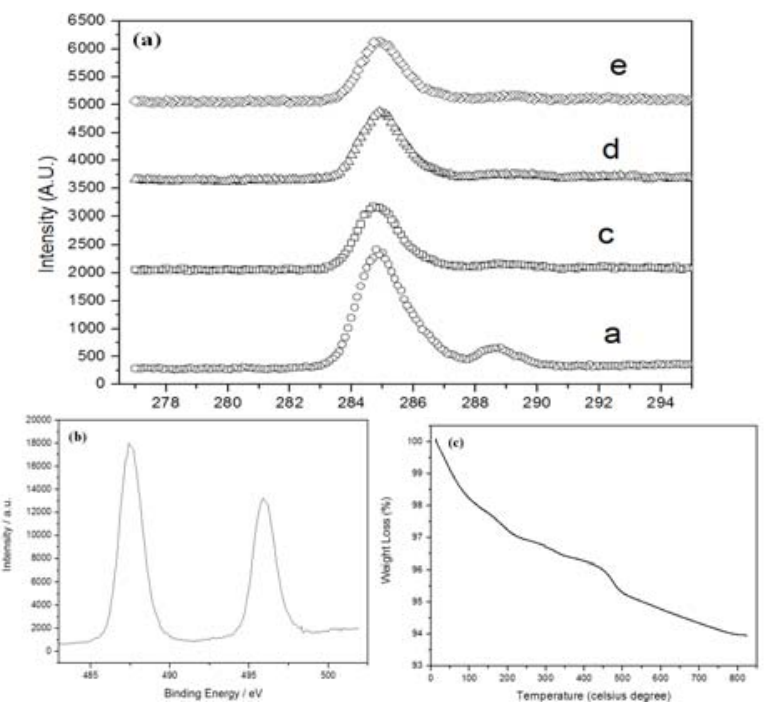

Figure 4. (a)XPS C1s spectrum of sample a, c, d, e.(b) Sn 3d spectrum of XPS of sample e.

We hypothesize two reasons for driving forces of phase transformation; first, the chemical moieties of urease might act as catalyst to facilitate the hydrolysis, condensation and crystallization of tin oxides; second, the inner surface of amorphous shell which contacts the urease might possess relatively high surface energy; the tendency to reducing surface energy might be the another factor to carry out the crystallization. Aizenberg have demonstrated that the transformation of amorphous $\mathrm{CaCO}_{3}$ into calcite required sufficient removal of the $\mathrm{H}_{2} \mathrm{O}$ associated with the amorphous phase ${ }^{[15]}$. Kröger also suggested the numerous rectangular pores (size 100-200 nm) present within the rutile $\mathrm{TiO}_{2}$ microspheres may act as $\mathrm{H}_{2} \mathrm{O}$ release channels that enable the crystallization process to occur ${ }^{[\mathrm{Ba}]}$. Thus, pores seem to be functioned as pathways for water exclusion and dehydration. In our experiment, the initial pores of amorphous tin oxides might be arisen from phase transformation process; these pores might provide more chance for water exclusion and dehydration, thus, facilitate the crystallization of pore walls of tin oxides; and further crystallization also produce more pores for further water exclusion. Finally, the crystalline porous tin oxides were obtained. This might explain the phenomena that the pores forming process is accompanied with crystallization. However, there is another question; why the relative large pores $(7 \sim 14 \mathrm{~nm})$ of sample $\mathrm{c}$ are gradually replaced by the uniform $3.3 \mathrm{~nm}$ pores of sample e with the increasing reaction time. The explanation might be following: hydrolyzed tin species continually deposit on the inner surface of large pores, and the confinement effect of pores could assist the phase transformation of amorphous tin oxides. (It was reported that small confinements can altered the reaction kinetics of crystal growth ${ }^{[16]}$ ) During this process, the large pores were gradually filled with newly grew tin oxides, thus, the large pore sizes were diminished to $3.3 \mathrm{mn}$ gradually.

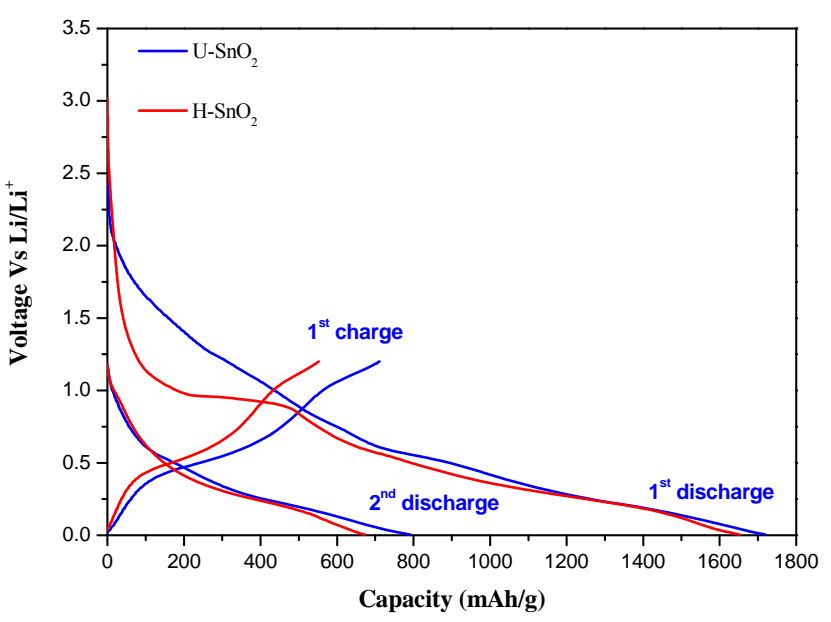

Figure 5 the galvanostatic voltage profiles between $0.005 \mathrm{~V}$ and $1.20 \mathrm{~V}$ for initial three discharge and charge curves of $\mathrm{U}-\mathrm{SnO}_{2}$ and $\mathrm{H}-\mathrm{SnO}_{2}$; insert, the cyclic performance of $\mathrm{U}-\mathrm{SnO}_{2}$ and $\mathrm{H}-\mathrm{SnO}_{2}$ up to the fiftieth cycle at the same current density, $200 \mathrm{~mA} / \mathrm{g}$

Since tin oxides have immense potentials as gas sensor and anode material for lithium ion battery, the electrode and sensor performance of urease mediated tin oxides (namely $\mathrm{U}-\mathrm{SnO}_{2}$ ) was tested; for comparison, the performances of porous tin oxides prepared by hydrothermal method (namely $\mathrm{H}-\mathrm{SnO}_{2}$ ) was also tested. Tin oxides have been proposed as alternative anode materials for lithium ion battery on the basis of their low working voltage, higher theoretical reversible specific capacity (e.g.,782 mAh g ${ }^{-1}$ for $\mathrm{SnO}_{2}$ based on the stoichiometry of $\left.\mathrm{Li}_{4.4} \mathrm{Sn}\right)^{[18]}$. However, the practical application of $\mathrm{SnO}_{2}$ is hindered by poor material cyclability arising from the large specific volume change in the discharging ( $\mathrm{Li}-\mathrm{Sn}$ alloying) and charging ( $\mathrm{Li}-\mathrm{Sn}$ dealloying) reactions, which causes stress-induced material failure and the loss of electrical contact at the anode. The porous structure might be one possible way to 
enhance the cyclability of tin oxide for the cavities can provide a sufficient space to sustain the volume change associated with $\mathrm{Li}$ insertion and extraction. The anodic performance of $\mathrm{SnO}_{2}$ is evaluated over the potential range from 0.005 to $1.2 \mathrm{~V}$ (versus $\mathrm{Li} / \mathrm{Li}^{+}$) by a standard method based on a $\mathrm{SnO}_{2} / \mathrm{Li}$ half cell, where $\mathrm{SnO}_{2}$ and lithium foil serve as positive and negative electrodes, respectively. Fig.5 shows initial three discharge and charge curves of $\mathrm{U}_{-} \mathrm{SnO}_{2}$. A high first discharge capacity $\left(1720 \mathrm{mAh} \mathrm{g}^{-1}\right)$ has been observed for $\mathrm{U}-\mathrm{SnO}_{2}$. This is normally attributed to irreversible reactions (e.g., the formation of $\mathrm{Li}_{2} \mathrm{O}$ or decomposition of electrolyte) occurring during the first discharge. Despite the large irreversible loss, a high reversible discharge capacity of $790 \mathrm{mAh} \mathrm{g}^{-1}$ is still attained in the first charge. Similar profile was observed on the $\mathrm{H}-\mathrm{SnO}_{2}$ electrode. It should be noted that the U$\mathrm{SnO}_{2}$ show initial columbic efficiencies of approximately $45.9 \%$ which is higher than that of $\mathrm{H}-\mathrm{SnO}_{2}(40.6 \%)$ and reported $\mathrm{SnO}_{2}$ nanotubes $(39.31 \%)$ and nanopowers $(31.01 \%)^{[3 \mathrm{c}]}$. In Fig. 5, the $\mathrm{U}-\mathrm{SnO}_{2}$ electrodes exhibited a higher reversible specific capacity of over $413 \mathrm{mAhg}^{-1}$ up to the fiftieth cycle with relatively stable cyclic performance, whereas the $\mathrm{H}-\mathrm{SnO}_{2}$ electrode showed an accelerated capacity fading (only a capacity of $256 \mathrm{mAhg}^{-}$ ${ }^{1}$ was obtained after 50 cycles). The average capacity fading of the $\mathrm{U}-\mathrm{SnO}_{2}$ was estimated to be $1 \%$ per cycle after the second cycle, which was much smaller than that of the $\mathrm{H}-\mathrm{SnO}_{2}(1.26 \%)$ and other reported $\mathrm{SnO}_{2}$ nanomaterials ${ }^{[18]}$. We believe the enhanced electrochemical performance might be attributed from two factors; (1) the cavities of porous $\mathrm{SnO}_{2}$ accommodate the strain induced by the volume change during the electrochemical reaction; (2) the existence of a porous structure with large surface areas and short diffusion pathways for facile lithium-ion transport.

The gas-sensing properties of the $\mathrm{U}-\mathrm{SnO}_{2}$ and $\mathrm{H}-\mathrm{SnO}_{2}$ have also been investigated. Fig. 6 shows the sharp variation of the sensor resistance to different concentrations of the target gases $\left(\mathrm{H}_{2}\right)$ at the operating temperature of $300^{\circ} \mathrm{C}$ in synthetic air.

The sensing mechanism is based on surface reactions with gases in the atmosphere that cause a change in the semiconductor's resistance due to charge transfer between the adsorbate and the adsorbent. Initially, the $\mathrm{U}-\mathrm{SnO}_{2}$ sensor showed larger response to the $\mathrm{H}-\mathrm{SnO}_{2}$ at the low concentrations $(10,50 \mathrm{ppm})$. However, as the $\mathrm{H}_{2}$ concentration increased, the $\mathrm{U}-\mathrm{SnO}_{2}$ sensor demonstrated similar response to $\mathrm{H}-\mathrm{SnO}_{2}$. The enhanced sensing performance at low concentration might be arisen from higher surface area of $\mathrm{U}-\mathrm{SnO}_{2}$. The reversibility and repeatability of these sensors were satisfactory, as observed by repeating the tests many times without detecting any significant variation in the functional response.

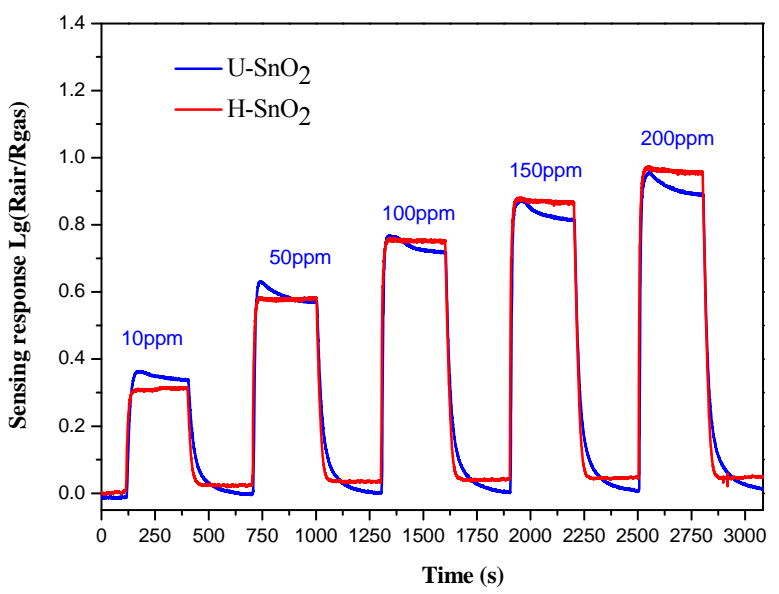

Figure 6.Real-time sensing responses to different concentrations of $\mathrm{H}_{2}$ gas in air for $\mathrm{U}-\mathrm{SnO}_{2}$ and $\mathrm{H}-\mathrm{SnO}_{2}$

In summary, we have demonstrated a completely novel, room-temperature pathway to crystalline porous tin oxides, which heretofore have only been accessible by high-temperature methods. By using urease as a biotemplate, high surface areas $\left(231.7 \sim 248.3 \mathrm{~m}^{2} \mathrm{~g}^{-1}\right)$ of porous tin oxides with narrow pore size distribution $(3.2 \sim 3.6 \mathrm{~nm})$ were obtained. The characterization of intermediates and final products reveal the key feature of strategy presented in this study is the stabilization of an amorphous tin oxide nanoshell by urease and its subsequent transformation to crystalline tin oxide. The phase transformation and removal of water might be the reason for pores forming process. The major portion of urease is not co-precipitated with the solid but is left in solution, which indicated the high purity of sample and the possibility for urease recovery; the obtained tin oxides showed improved cyclability when used as anode in lithium ion battery. Considering its environmental benign and energy-conserving reaction condition, it is thought that such a facile one pot pathway may ultimately offer means of porous tin oxides synthesis with good devices performance at a lower cost than traditional methods. To the author's knowledge, this work is the first report of porous oxide semiconductor induced by biomolecules at room temperature, and will open up new possibilities to produce other functional porous oxide semiconductors.

\section{ACKNOWLEDGMENT}

This work is financially supported by the Funding Project for Academic Human Resources Development in Institutions of Higher Learning under the Jurisdiction of Beijing Municipality.

\section{REFERENCES}

[1] a) V. Juttukonda, R. L. Paddock, J. E. Raymond, D. Denomme, A. E. Richardson, L. E. Slusher, B. D. Fahlman, J. Am. Chem. Soc. 2006, 128, 420. b) H. J. Ahn, H. C. Choi, K. W. Park, S. B. Kim, Y. E. Sung, J. Phys. Chem. B 2004, 108, 9815

[2] a) M.S. Park, G.X. Wang, Y.M. Kang, D. Wexler, S.X. Dou, H.K. Liu, Angew. Chem. Int. Ed. 2007, 46, 750. b) N.C. Li, C.R. Martin, J. Electrochem. Soc. 2001, 148, A164.

[3] a) Y. Wang, H. C. Zeng, J. Y. Lee, Adv. Mater. 2006, 18, 645. b) Y. Wang, J.Y. Lee, H.C. Zeng Chem. Mater. 2005, 17, 3899. c) M.S. Park, Y.M. Kang, G.X. Wang, S.X. Dou, H.K. Liu, Adv. Funct. Mater. 2008, 18, 455. 
[4] a) X.W. Lou, Y. Wang, C. Yuan, J.Y. Lee, L. Archer, Adv. Mater. 2006, 18, 2325. b) S. Han, B. Jang, T. Kim, S.M. Oh, T. Hyeon, Adv. Funct. Mater. 2005, 15, 1845.

[5] a) J. Ba, J. Polleux, M. Antonietti, M. Niederberger, Adv. Mater. 2005, 17, 2509. b) S. Yang, L. Gao, J. Am. Ceram. Soc. 2006, 89, 1742. c) S. Fujihara, T. Maeda, H. Ohgi, E. Hosono, H. Imai, S.H. Kim, Langmuir 2004, 20, 6476. d) R. Demir-Cakan, Y.S. Hu, M. Antonietti, J. Maier, M.M. Tiririci, Chem. Mater. 2008, 20, 1227. e) L. L. Li, W. M. Zhang, Q, Yuan, Z.X. Li, C. J. Fang, L. D. Sun, C. H. Yan, Crystal Growth \& Design 2008, 8, 4165. f) C. Velasquez, F. Rojas, J.M. Esparza, A. Oritz, A. Campero, J. Phys. Chem. B 2006, 110, 11823. g) T. Toupance, H.E. Hamzaoui, B.Jousseaume, H. Riague, I. Saadeddin, G. Campet, J. Brotz, Chem. Mater. 2006, 18, 6364. h) P. Yang, D. Zhao, I. Margolese, B.F. Chmelka, G. D. Stucky, Chem. Mater. 1999, 11, 2813. i) F. L. Chen, M. L. Liu, Chem. Commun. 1999, 18, 1829. j) Y.D. Wang, C.L. Ma, X.D.Sun, H.D. Li, Microporous Mesoporous Mater. 2001, 49, 171. k) N. L. Wu, C. Y. Tung, J. Am. Ceram. Soc. 2004, 87, 1741. 1) S. Takenaka, R. Takahashi, S. Sato, T. Sodesawa, F. Matsumoto, S. Yoshida Microporous Mesoporous Mater. 2003, 59, 123. m) G. C. Xi, Y. T. He, Q. Zhang, H. Q. Xiao, X. Wang, C. Wang, J. Phys. Chem. C 2008, 112,11645. n) H. Kim, J. Cho, J. Mater. Chem. 2008, 18, 771. o) Z. Wen, Q. Wang, J. Li, Adv. Funct. Mater. 2007, $17,2772$.

[6] a) J.L. Sumerel, W. Yang, D. Kisailus, J.C. Weaver, J.H. Choi, D.E Morse, Chem. Mater. 2003, 15, 4804. b) D. Kisailus, J.H. Choi, W.J. Yang, D.E. Morse, Adv. Mater. 2005, 17, 314. c) R.L.
Brutchey, E.S. Yoo, D.E. Morse, J. Am. Chem. Soc. 2006, 128, 10288.

[7] R. L. Brutchey, D.E. Morse, Chem. Rev. 2008, 11, 4915. b) M.B. Dickerson, K.H. Sandhage, R.R. Naik, Chem. Rev. 2008, 108, 4935.

[8] a) N. Kröger, M.B. Dickerson, G. Ahmad, Y. Cai, M.S. Haluska, K.H. Sandhage, N. Poulsen, V.C. Sheppard, Angew. Chem. Int. Ed. 2006, 45, 7239 .

[9] R. De la Rica, H. Matsui, Angew. Chem. Int. Ed. 2008, 47, 5415.

[10] M.T. Klem, M. Young, T. Douglas, J. Mater. Chem. 2008, 18, 3821.

[11] K. Takishima, T. Suga, G. Mamiya, Eur. J. Biochem. 1988, 175, 151.

[12] H. C. Tsai, R. A. Doong, Biosens. Bioelectron. 2005, 20, 1796.

[13] a) D. Kisailus, Q. Truong, Y. Amemiya, J. Weaver, D.E. Morse, Proc. Natl. Acad. Sci. USA 2006, 103, 5652. b) S.Y. Lee, X.Y. Gao, H. Matsui, J. Am. Chem. Soc. 2007, 129, 2954.

[14] a) S.H. Yu, H. Colfen, J. Mater. Chem. 2004, 14, 2124. b) A.W. Xu, Y.R. Ma, H. Colfen, J. Mater. Chem., 2007, 17, 415.

[15] J. Aizenberg, D.A. Muller, J.L. Grazul, D.R.Hamann, Science 2003, 299, 1205.

[16] E. Loste, R.J. Park, J. Warren, F.C. Meldrum, Adv. Funct. Mater. 2004, 14, 1211.

[17] a) I.A. Courtney, J.R. Dahn, J. Electrochem. Soc. 1997, 144, 2045. b) W. Liu, X. Huang, Z. Wang, H. Li, L. Chen, J. Electrochem. Soc.
145 , 